\title{
HUBUNGAN SENAM HAMIL DENGAN PROSES PERSALINAN KALA I DAN II PADA PRIMIGRAVIDA DI PMB WILAYAH KERJA PUSKESMAS SIDOREJO
}

\author{
The Relationship between Pregnant Gymnastics and the Process of Labor Stages I and II on \\ Primigravida at PMB, Sidorejo Primary Health Care Working Area Lubuklinggau City
}

\author{
Metha Fahriani, Rini Yuli Astini, Mika Oktarina \\ Program Studi Kebidanan STIKES Tri Mandiri Sakti Bengkulu \\ Email : methafahriani42@gmail.com
}

\begin{abstract}
The duration of labor can be caused by many factors, including inadequate contractions, fetal factors and birth canal factors. As a result of the first and second stages of the disease, infection is one of the factors causing maternal death. The purpose of this study was to study the relationship between pregnancy exercise with the delivery process of the first and second stages of primigravida in the PMB of the Sidorejo Public Health Center in Lubuklinggau. This type of research is an analytic survey research with cross sectional approach. The population in this study were all primigravida mothers who gave birth in three PMB in the working area of Sidorejo Public Health Center in Lubuklinggau City in April to May 2019 as many as 30 people. Samples were taken using the Total Sampling technique. The data used are primary data and secondary data. Data were analyzed using univariate and bivariate analysis with Chi-Square $(\square 2)$ and Contingency Coefficient $(C)$ tests. The results obtained from 30 mothers there were $19(63.3 \%)$ people with childbirth in the first and second stages of labor not long, 16 (53.3) people with irregular pregnancy exercises, there was a significant relationship between pregnancy exercise with the first stage of labor and II in primigravidas with the strong relationship category. It is expected that the Puskesmas can improve counseling about the benefits of pregnancy exercises, increase the schedule for implementing pregnancy exercises, and perform ball pick-up techniques for pregnant women to do pregnancy exercises so that the delivery process can run smoothly.
\end{abstract}

Keywords : The Process of Labor, Pregnant Gymnastic, Primigravida

\begin{abstract}
Abstrak
Lama persalinan dapat disebabkan oleh banyak faktor, antara lain kontraksi tidak adekuat, faktor janin dan faktor jalan lahir. Akibat dari kala I dan II yang memanjang adalah terjadinya infeksi yang merupakan salah satu faktor penyebab kematian ibu. Tujuan penelitian ini adalah untuk mempelajari hubungan antara senam hamil dengan proses persalinan kala I dan II pada primigravida di PMB wilayah kerja Puskesmas Sidorejo Kota Lubuklinggau. Jenis penelitian ini merupakan penelitian Survey analitik dengan pendekatan Cross Sectional. Populasi dalam penelitian ini adalah seluruh ibu primigravida yang bersalin di tiga PMB wilayah kerja Puskesmas Sidorejo Kota Lubuklinggau di bulan April sampai Mei 2019 sebanyak 30 orang. Sampel diambil menggunakan teknik Total Sampling. Data yang digunakan adalah data primer dan data sekunder. Data dianalisis menggunakan analisis univariat dan bivariat dengan uji Chi-Square $(\square 2)$ dan uji Contingency Coefficient (C). Hasil penelitian didapatkan dari 30 ibu terdapat $19(63,3 \%)$ orang dengan proses persalinan kala I dan II tidak lama, $16(53,3)$ orang dengan senam hamil tidak teratur, ada hubungan yang signifikan antara senam hamil dengan proses persalinan kala I dan II pada primigravida dengan kategori hubungan kuat. Diharapkan pihak Puskesmas dapat meningkatkan penyuluhan tentang manfaat senam hamil, menambah jadwal pelaksanaan senam hamil, dan melakukan teknik jemput bola pada ibu hamil untuk melakukan senam hamil agar proses persalinan dapat berjalan dengan lancar.
\end{abstract}

Kata kunci : Proses Persalinan, Senam Hamil, Primigravida 


\section{PENDAHULUAN}

Kematian dan Kesakitan Ibu merupakan masalah kesehatan yang serius di Negara berkembang. Menurut World Health Organization (WHO) tahun 2014 Angka Kematian Ibu di dunia yaitu sebesar 289.000 jiwa. Kematian ibu adalah jumlah kematian ibu selama masa kehamilan, melahirkan dan dalam periode 42 hari setelah persalinan (nifas), yang merupakan akibat semua sebab yang terkait dengan atau diperberat oleh kehamilan atau penangannya, tetapi bukan disebabkan oleh kecelakaan atau cedera (WHO, 2015).

Angka kematian ibu (AKI) telah mengalami penurunan dari 359 kematian ibu per 100.000 kelahiran hidup menjadi 305 kematian ibu per 100.000 kelahiran hidup berdasarkan hasil Survey Penduduk Antar Sensus (SUPAS) tahun 2015. Sedangkan target rencana strategis kementerian kesehatan tahun 2015-2019 adalah 306 per 100.000 kelahiran hidup pada tahun 2019. Angka tersebut juga masih jauh dari target Sustainable Development Goals (SDGs) yaitu mengurangi angka kematian ibu hingga dibawah 70 per 100.000 kelahiran hidup pada tahun 2030 (Kemenkes RI, 2016). Penyebab langsung angka kematian ibu antara lain: perdarahan $42 \%$, eklamsia/preekalmsia $13 \%$, abortus $11 \%$, infeksi $10 \%$, partus lama/ persalinan macet $9 \%$, dan penyebab lain $15 \%$ (SUPAS, 2015).

besar) dan faktor jalan lahir. Kontraksi yang tidak adekuat dan faktor janin dapat menyebabkan persalinan kala I dan II menjadi memanjang. Akibat dari kala I dan II yang memanjang adalah terjadinya infeksi yang merupakan salah satu faktor penyebab kematian ibu. Faktor jalan lahir juga menyebabkan morbiditas pada ibu berupa terjadi luka perineum yang sangat rentan terjadi infeksi jika tidak ditangani dengan baik (Eniyati, 2010).

Upaya pemerintah dalam menurunkan angka morbiditas dan mortalitas ibu adalah mengadakan program pelayanan antenatal terpadu. Pelayanan antenatal terpadu adalah pelayanan antenatal yang komprehensif dan berkualitas yang diberikan kepada semua ibu hamil. Salah satu intervensi kesehatan yang efektif adalah pelayanan antenatal yaitu senam hamil. Bidan dalam melakukan pelayanan pada ibu hamil memiliki wewenang untuk membimbing dalam melakukan senam hamil (Kemenkes RI, 2017).
Proses persalinan pada ibu bersalin normal berlangsung dalam waktu kurang dari 24 jam, dimana terbagi dalam empat kata. Kala I pada untuk primigravida berlangsung 12 jam sedangkan multigravida sekitar 8 jam. Persalinan kala II biasanya untuk primigravida berlangsung 50 menit dan multigravida 30 menit. Kala III biasanya berlangsung 5-30 menit setelah lahir bayi, kala IV dimulai dari saat lahirnya plasenta sampai dua jam pertama post partum (Manuaba, 2015).

Menurut Sulistyawati (2010) persalinan kala II dimulai saat serviks berdilatasi penuh berakhir saat bayi lahir. Bagi primigravida kemajuan persalinan dapat berlangsung $1 \mathrm{~cm} / 2$ jam dan pada multigravida relatif lebih singkat yakni $1 \mathrm{~cm} / 1$ jam. Persalinan yang diikuti dengan kejadian memanjangnya waktu pada kala I dan II mempunyai dampak kepada ibu dan janin. Dampak yang akan terjadi pada ibu kala I dan II lama yaitu akan terjadi kelelahan sampai mengakibatkan dehidrasi, infeksi pada ibu terutama jika sudah terjadi pecahnya selaput ketuban, hingga perdarahan karena atonia uteri, dan ruptur uteri.

Proses persalinan dipengaruhi oleh beberapa faktor yang disebut 5P, yaitu power, passage, passenger, penolong, dan psikis. Lama persalinan dapat disebabkan oleh banyak faktor, namun yang prinsip adalah kontraksi tidak adekuat, faktor janin (malpresentasi, malposisi, janin

Senam hamil adalah program kebugaran yang diperuntukkan bagi ibu hamil. Senam hamil memiliki prinsip gerakan khusus yang disesuaikan dengan kondisi ibu hamil. Kegiatan ini bertujuan untuk menyehatkan ibu dan membuat ibu hamil agar nyaman, aman dari sejak bayi dalam kandungan hingga lahir. Pelaksanaan senam hamil dianjurkan saat usia kehamilan diatas 20 minggu dikarenakan saat kehamilan dibawah 20 minggu perlekatan janin dalam rahim belum kuat (Andries, 2015).

Di Provinsi Sumatera Selatan yang terdiri dari 13 kabupaten dan 4 kota angka kematian ibu pada tahun 2015 adalah sebesar 165 per 100.000 kelahiran hidup, sedangkan pada tahun 2016 mengalami penurunan yaitu 142 per 100.000 kelahiran hidup. Jumlah kasus kematian ibu per kabupaten/kota di provinsi Sumatera Selatan pada tahun 2016 yang tertinggi adalah kabupaten Oku Timur yaitu 16 kasus dan terendah adalah kota Pagaralam dan kabupaten Pali yaitu 3 kasus. 
Berdasarkan data Dinkes Kota Lubuklinggau data persalinan tahun 2018 sebanyak 3.925 persalinan (547 bumil yang mengikuti senam hamil) dan untuk Puskesmas Sidorejo sebanyak 378 persalinan (86 bumil yang mengikuti senam hamil), merupakan 5 tertinggi dari 9 Puskesmas yang ada di Kota Lubuklingau. Dengan tertinggi pertama Puskesmas Citra Medika 681 persalinan (88 bumil yang mengikuti senam hamil), kedua Puskesmas Megang 650 persalinan (10 bumil yang mengikuti senam hamil), ketiga Puskesmas Perumnas 624 persalinan (0 bumil yang mengikuti senam hamil) dan keempat Puskesmas Simpang Priuk 535 persalinan (36 bumil yang mengikuti senam hamil) (Dinkes Kota Lubuklinggau, 2019).

Hasil survei awal yang dilakukan oleh peneliti pada 23 Desember 2018 didapatkan 6 Praktek Mandiri Bidan (PMB) yang aktif menolong persalinan dari 9 PMB yang ada di wilayah Puskesmas Sidorejo, selanjutnya peneliti melakukan wawancara langsung pada 7 orang ibu bersalin, 4 orang tidak melakukan senam hamil dikarenakan tidak mengetahui manfaat dari senam hamil terhadap lamanya proses persalinan dan 3 orang melakukan senam hamil dikarenakan disuruh oleh bidan untuk melakukan senam hamil.

Rumusan masalah dalam penelitian ini adalah apakah terdapat hubungan senam hamil terhadap proses persalinan kala I dan II pada primigravida di PMB wilayah kerja Puskesmas Sidorejo Kota Lubuklinggau?. Tujuan penelitian ini adalah untuk mempelajariadanya hubungan antara senam hamil dengan proses persalinan kala I dan II pada primigravida di PMB wilayah kerja Puskesmas Sidorejo Kota Lubuklinggau.

\section{BAHAN DAN METODE}

Jenis penelitian ini merupakan penelitian Survey analitik dengan pendekatan Cross Sectional. Populasi dalam penelitian ini adalah seluruh ibu primigravida yang bersalin di tiga PMB wilayah kerja Puskesmas Sidorejo Kota Lubuklinggau di bulan April sampai Mei 2019 sebanyak 30 orang. Sampel diambil menggunakan teknik Total Sampling. Data yang digunakan adalah data primer dan data sekunder. Data dianalisis menggunakan analisis univariat dan bivariat dengan uji Chi-Square $\left(\chi^{2}\right)$ dan uji Contingency Coefficient (C).

\section{HASIL DAN PEMBAHASAN}

\section{Analisa Univariat}

Berdasarkan Tabel 1 dapat dilihat dalam variabel persaliman, bahwa dari 30 orang ibu primigravida yang bersalin di PMB wilayah kerja Puskesmas Sidorejo Kota Lubuklinggau terdapat 11 ibu primigravida bersalin yang proses persalinannya lama dan 19 ibu primigravida bersalin yang proses persalinannya tidak lama. Variabel Senam Hamil, bahwa dari 30 orang ibu primigravida yang bersalin di PMB wilayah kerja Puskesmas Sidorejo Kota Lubuklinggau terdapat $14 \mathrm{ibu}$ primigravida yang bersalin melakukan senam hamil teratur dan $16 \mathrm{ibu}$ primigravida yang bersalin melakukan senam hamil tidak teratur.

Tabel 1. Distribusi Frekuensi Proses Persalinan dan Senam Hamil Kala I dan II pada Primigravida di PMB Wilayah Kerja Puskesmas Sidorejo

\begin{tabular}{lcc}
\hline Variabel & Frekuensi & Persentase \\
\hline Persalinan & & \\
$\quad$ Lama & 11 & 36,7 \\
$\quad$ Tidak Lama & 19 & 63,3 \\
Senam Hamil & & \\
$\quad$ Tidak teratur & 16 & 53,3 \\
$\quad$ Teratur & 14 & 46,7 \\
\hline Jumlah & $\mathbf{3 0}$ & $\mathbf{1 0 0}$ \\
\hline
\end{tabular}

\section{Analisa Bivariat}

Analisis bivariat dilakukan untuk mengetahui hubungan antara senam hamil dengan proses persalinan kala I dan II pada Primigravida di PMB wilayah kerja Puskesmas Sidorejo. Tabel 2 menunjukkan bahwa dari 16 ibu primigravida yang bersalin melakukan senam hamil tidak teratur, $10 \mathrm{ibu}$ bersalin diantaranya proses persalinan lama dan 6 ibu bersalin lainnya proses persalinannya tidak lama dikarenakan his yang adekuat 2 responden, janin kecil 1 responden, induksi 2 responden dan pecah ketuban 1 responden. Dari 14 ibu primigravida yang bersalin melakukan senam hamil teratur, 1 ibu bersalin diantaranya proses persalinan lama dikarenakan his yang tidak adekuat dan 13 ibu bersalin lainnya proses persalinannya tidak lama.

Hasil uji Chi-Square diperoleh nilai $x^{2}=9,853^{a}$ dengan $p=0,002<0,05$ berarti signifikan makaHo ditolak dan Ha diterima.Artinya terdapat hubungan yang signifikan antarasenam hamil dengan proses persalinan kala I dan II pada primigravidadi PMB wilayah kerja Puskesmas Sidorejo. 
Tabel 2. Hubungan Senam Hamil dengan Proses Persalinan Kala I dan II pada Primigravida di PMB Wilayah Kerja Puskesmas Sidorejo

\begin{tabular}{|c|c|c|c|c|c|c|c|c|c|}
\hline \multirow{3}{*}{ Senam Hamil } & \multicolumn{4}{|c|}{ Persalinan } & \multirow{2}{*}{\multicolumn{2}{|c|}{ Total }} & \multirow{3}{*}{$x^{2}$} & \multirow{3}{*}{$p$} & \multirow{3}{*}{ C } \\
\hline & \multicolumn{2}{|c|}{ Lama } & \multicolumn{2}{|c|}{ Tidak Lama } & & & & & \\
\hline & $f$ & $\%$ & $\mathbf{F}$ & $\%$ & $f$ & $\%$ & & & \\
\hline Tidak teratur & 10 & 62,5 & 6 & 37,5 & 16 & 100 & \multirow{3}{*}{9,853} & \multirow{3}{*}{0,002} & \multirow{3}{*}{0,497} \\
\hline Teratur & 1 & 7,1 & 13 & 92,9 & 14 & 100 & & & \\
\hline Jumlah & 11 & 36,7 & 19 & 63,3 & 30 & 100 & & & \\
\hline
\end{tabular}

Hasil uji Contingency Coefficientdidapat nilai $\mathrm{C}=0,497$ dengan $\mathrm{p}=0,002$ berarti signifikan, dengan kategori hubungan kuat.

Berdasarkan hasil penelitian, diketahui bahwa dari 30 orang ibu primigravida yang bersalin di PMB wilayah kerja Puskesmas Sidorejo Kota Lubuklinggau terdapat 19 ibu primigravida bersalin yang proses persalinannya tidak lama dan $11 \mathrm{ibu}$ primigravida bersalin yang proses persalinannya lama disebabkan oleh berbagai faktor, yaitu his tidak adekuat, lilitan tali pusat, primi tua, distosia dan kelainan letak. Untuk proses persalinan lamanya kala I untuk primigravida berlangsung 12 jam sedangkan multigravida sekitar 8 jam Lamaya kala II untuk primigravida 50 menit dan multigravida 30 menit.

Dilihat dari data diatas dapat disimpulkan bahwa proses persalinan pada primigravida masih banyak yang berlangsung lama, karena ibu tidak mengetahui salah satu faktor yang mempengaruhi persalinan adalah power yang didapat dari tenaga meneran ibu. Tenaga meneran bisa didapat dengan rajin melakukan senam hamil secara teratur.

Hasil penelitian ini sejalan dengan penelitian Amalina (2015) yang berjudul "Hubungan rutinitas senam hamil dengan waktu persalinan pervaginam pada primigravida di Rumah Sakit Panti Wilasa Semarang" menyatakan ada hubungan antara rutinitas senam hamil dengan waktu persalinan pervaginam pada primigravida di Rumah Sakit Wilasa Semarang.

Berdasarkan hasil penelitian, diketahui bahwa dari 30 orang ibu primigravida yang bersalin di PMB wilayah kerja Puskesmas Sidorejo Kota Lubuklinggau terdapat 16 ibu primigravida yang bersalin melakukan senam hamil tidak teratur, sedangkan 14 ibu primigravida yang bersalin lainnya melakukan senam hamil secara teratur.

Menurut penelitian Yanuaria (2016) yang meneliti tentang penerapan senam selama hamil dan efektifitasnya terhadap lama persalinan, robekan perineum dan hasil luaran bayi. Didapatkan hasil bahwa senam hamil merupakan pelayanan prenatal efektif membawa dampak positif terhadap ibu hamil dalam menjalani proses persalinan dan kelahiran bayi, dibanding ibu hamil yang tidak melakukan senam hamil. Sebanyak 96,7\% lama persalinan menjadi lebih singkat.

Berdasarkan hasil penelitian didapatkan bahwa dari 16 ibu primigravida yang bersalin melakukan senam hamil tidak teratur, $10 \mathrm{ibu}$ bersalin diantaranya proses persalinan lama, dan $6 \mathrm{ibu}$ bersalin lainnya proses persalinannya tidak lama dikarenakan his yang adekuat 2 responen, janin kecil 1 responden, induksi 2 responden dan pecah ketuban 1 responden. Ibu bersalin yang tidak pernah mengikuti senam hamil secara sering atau teratur sebagian besar mengalami proses persalinan tidak normal karena ibu jarang maupun tidak pernah mengikuti latihan-latihan fisik atau olahraga selama hamil sehingga otot-otot dinding perut dan otot-otot dasar panggul menjadi tidak kaku dan tidak dapat berfungsi dengan sempurna dalam proses persalinan.

Dari 14 ibu primigravida yang bersalin melakukan senam hamil teratur, 1 ibu bersalin diantaranya proses persalinan lama dikarenakan his yang tidak adekuatdan 13 ibu bersalin lainnya proses persalinannya tidak lama.

Hasil uji statistic Continuity Correction didapatkan bahwa hubungan yang signifikan antara senam hamil dengan proses persalinan kala I dan II pada Primigravida di PMB wilayah kerja Puskesmas Sidorejo Kota Lubuklinggau. Hal ini sejalan dengan Tandiono (2017) yang menyatakan bahwa terdapat perbedaan bermakna lama persalinan antara ibu hamil yang melakukan senam hamil dan tidak melakukan senam hamil. 
Hasil uji Contingency Coefficient didapat kategori hubungan kuat. Kondisi ini menunjukkan bahwa pelaksanaan senam hamil merupakan faktor yang dominan mempengaruhi lamanya proses persalinan. Saran bagi ibu yaitu agar menerapkan pelaksanaan senam hamil secara teratur pada kehamilan berikutnya agar proses persalinan dapat lebih cepat. Hal ini sejalan dengan penelitian Rahmawati (2016) bahwa ada hubungan senam hamil terhadap lamanya proses persalinan pada ibu bersalin

Dari hasil uji diatas dapat disimpulkan bahwa ada hubungan senam hamil dengan proses persalinan kala I dan II pada Primigravida di PMB wilayah kerja Puskesmas Sidorejo Kota Lubuklinggau dengan kategori kuat, signifikan. Dengan 1 dari 14 responden yang melakukan senam hamil secara teratur tetapi proses persalinan lama karena his yang tidak adekuat. Dan 6 dari 16 responden yang tidak melakukan senam hamil secara teratur tetapi proses persalinan tidak lama disebabkan oleh his yang adekuat 2 responden, janin kecil 1 responden, induksi 2 responden dan pecah ketuban 1 responden.

Tindakan yang harus dilakukan oleh Puskesmas antara lain dengan melakukan penyuluhan yang lebih intens lagi tentang manfaat senam hamil, melengkapi sarana dan prasarana senam hamil seperti matras, kaca, sound system dan lain-lain, melakukan jemput bola bagi ibu hamil untuk melakukan senam hamil di Puskesmas Sidorejo Kota Lubuklinggau serta menambah jadwal pelaksanaan senam hamil dari 2 kali dalam sebulan menjadi 2 kali dalam seminggu.

Tindakan yang harus dilakukan bagi PMB atau Bidan dapat melaksanakan senam hamil di PMB masing-masing atau memberikan informasi kepada ibu hamil untuk melakukan senam hamil di Puskesmas Sidorejo Kota Lubuklinggau. Sedangkan yang harus dilakukan oleh ibu hamil sendiri adalah mengerti tentang manfaat senam hamil dan mau mengikuti senam hamil di Puskesmas Sidorejo Kota Lubuklinggau dan dapat mengulanginya kembali di rumah.

Banyak manfaat dari melakukan senam hamil diantaranya memperbaiki sirkulasi darah, meningkatkan keseimbangan otot-otot, mengurangi risiko gangguan gastrointestinal, termasuk sembelit, mengurangi kejang kaki/ kram, menguatkan otot perut, dan mempercepat penyembuhan setelah kehamilan (Maryunani, 2011).

\section{KESIMPULAN DAN SARAN}

Berdasarkan hasil penelitian dapat disimpulkan bahwa dari $30 \mathrm{ibu}$ hamil terdapat terdapat 11 responden mengalami proses persalinan lama dan 19 mengalami proses persalinan tidak lama, dimana diantaranya 16 responden tidak melakukan senam hamil secara teratur dan 14 responden melakukan senam hamil secara teratur. Ada hubungan yang signifikan antara senam hamil dengan proses persalinan kala I dan II pada primigravida dengan kategori hubungan kuat. Diharapkan Puskesmas dapat meningkatkan penyuluhan tentang manfaat senam hamil, menambah jadwal pelaksanaan senam hamil dan melakukan jemput bola ke rumah ibu hamil.

\section{DAFTAR PUSTAKA}

Amalina. (2015). Hubungan Rutinitas Senam Hamil dengan Waktu Persalinan Pervaginam pada Primigravida di Rumah Sakit Panti Wilasa Semarang. Thesis. Fakultas Ilmu Kesehatan Universitas Muhammadiyah Semarang. https://jurnal.unimus.ac.id/index.php/kedok teran/article/view/2581

Andries, S., Adam, S., Montolalu, A. (2015). Pengaruh penyuluhan tentang senam hamil terhadap peningkatan pengetahuan ibu hamil.Jurnal Ilmiah Bidan.Jakarta: EGC.Vol 3 No 2 Bulan Juli Desember.

https://media.neliti.com/media/publications 192092

Dinkes Kota Lubuklinggau. (2018). Profil KesehatanKota Lubuklinggau 2018. Lubuklinggau:Dinas Kesehatan Kota.

Dinkes Provinsi Sumatera Selatan. (2016). Profil KesehatanProvinsi Sumatera Selatan 2016. Palembang:Dinas Kesehatan Provinsi.

Eniyati, Putri, M. (2010). Asuhan Kebidanan pada Ibu Bersalin. Yogyakarta: Pustaka Pelajar.

Kemenkes RI. (2016). Profil Kesehatan Indonesia 2016. Jakarta: Kementerian Kesehatan RI.

Kemenkes RI.(2017).Senam Hamil: Dilakukan setiap hari untuk memperlancar prose persalinan. Jakarta.

Manuaba, IBG. (2015). Ilmu Kebidanan, Penyakit Kandungan dan Keluarga Berencanauntuk Pendidikan bidan. Jakarta: Penerbit EGC.

Rahmawati. (2016). Hubungan Senam Hamil Terhadap Lamanya Proses Persalinan pada Ibu Bersalin di Wilayah Kerja Puskesmas Bayat Klaten. Jurnal Involusi Kebidanan, Vol. 6, No. 11, Januari 2016, 30-37 
http://ejournal.poltektegal.ac.id/index.php/si klus/article/downloadSuppFile/473/202

SUPAS. (2015). Profil Penduduk Indonesia: Angka Kematian Ibu. Jakarta: Kepala Badan Pusat Statistik.

WHO. (2015). Low Birthweight: Country, Regional And Global Estimates. United Nations Children's Fund And World Health Organization 2015. New York. USA. Government Printing Office.
Yanuaria, S. P., Djuwantono, T., Sedjati, A., et al. (2016).Penerapan Senam selama Hamil dan Efektifitasnya terhadap Lama Persalinan, Robekan Perineum dan Hasil Luaran Bayi. IJEMC. Volume 3 No 2 Bulan Juni http://journal.unusa.ac.id/index.php/jhs/arti cle/download/91/82 